\title{
Direct Power Control Topologies for DFIG-Based Wind Plants
}

\author{
Alireza Nazari and Hossein Heydari, Member, IACSIT
}

\begin{abstract}
This paper compares the performance of alternative direct power control strategies applied to doubly fed induction generator (DFIG). These methods directly investigate stator active and reactive power variations within a fixed sampling period. Simulations are performed using detailed models in Simulink/Matlab. Transient performance and steady state operation of the DFIG-based wind plants are illustrated.
\end{abstract}

Index Terms-Doubly fed induction generator (DFIG), direct power control (DPC), transient performance, steady state operations.

\section{INTRODUCTION}

Doubly fed induction generators (DFIGs) currently dominate the renewable energy market. Over the last decades, DFIG-based wind turbines have been preferred option for high capacity wind farms because of its ability to control active and reactive power exchange with the network. So, DFIGs in compare with the other wind generators have variable speed operation. Its variable speed operation caused reducing the dynamic power on the tower and gearbox. In the development of WT techniques, nowadays, DFIG is becoming more popular because of its unique characteristics such as high efficiency, low cost and flexible control. A schematic of a DFIG-based wind energy generation system is shown in Fig.1.

Control of DFIG wind turbine systems is rudimentarily based on either stator flux-oriented [1], [2] or stator-voltageoriented vector control [3], [4]. This method decouples the rotor current into active and reactive power components. Control of the active and reactive powers is achieved with a rotor current controller. One main drawback of this system is that its performance depends highly on accurate machine parameters such as stator, rotor resistances, and inductances.

The next generation of power control methods is direct torque control (DTC) [5], [6]. DTC degrades the use of machine parameters and reduces the complexity of vector control algorithms. The DTC method directly controls machine torque and flux by selecting voltage vectors from a look-up-table using the stator flux and torque information. One problem with the basic DTC scheme is that its performance deteriorates during starting and low-speed operations.

Based on the principles of DTC strategy, direct power control (DPC) was developed for three-phase pulse width

Manuscript received June 15, 2012; revised July 24, 2012.

Alireza Nazari is with High Voltage Lab.-Iran Uni of Sci and Tech.University St.-Hengam Avenue.-Resalat Square, Iran (email:nazari@elec.iust.ac.ir) modulation (PWM) rectifiers [7]-[9]. Converter switching states were selected from an optimal switching table based on instantaneous errors of active and reactive powers and the angular position of converter terminal voltage vector [7],[8], or virtual flux that is the integration of the converter output voltage[9]. More recently, DPC control of DFIGbased wind turbine systems has been proposed

In this paper, different direct power control performances are compared. The paper is organized as follows. Section II depicts a detailed model of DFIG. Section III gives an overview of different kinds of direct power control of DFIG. Simulation results for a $2 \mathrm{MW}$ DFIG generation system are presented in section IV. At last, conclusions are revealed in section $\mathrm{V}$.

\section{DFIG DetAILED Model AND DPC}

\section{A. DFIG Model}

The mathematical model of the DFIG used in this paper is presented here using the $\mathrm{d}-\mathrm{q}$ synchronous reference frame. The equations for the stator and rotor windings can be written as:

$$
\begin{aligned}
& \left\{\begin{array}{l}
u_{s d}=R_{S} i_{s d}+\frac{d}{d t} \psi_{s d}-w_{1} \psi_{s q} \\
u_{s q}=R_{S} i_{s q}+\frac{d}{d t} \psi_{s q}+w_{1} \psi_{s d}
\end{array}\right. \\
& \left\{\begin{array}{l}
u_{r d}=R_{r} i_{s d}+\frac{d}{d t} \psi_{r d}-w_{s} \psi_{r q} \\
u_{r q}=R_{r} i_{r q}+\frac{d}{d t} \psi_{r q}+w_{r} \psi_{r d}
\end{array}\right.
\end{aligned}
$$

The $d-q$ synchronous reference frame equations of the stator flux and rotor may be written also as:

$$
\begin{gathered}
\left\{\begin{array}{l}
\psi_{s d}=L_{S} i_{s d}+L_{m} i_{r d} \\
\psi_{s q}=L_{s} i_{s q}+L_{m} i_{r q}
\end{array}\right. \\
\left\{\begin{array}{l}
\psi_{r d}=L_{m} i_{s d}+L_{r} i_{r d} \\
\psi_{r q}=L_{m} i_{s q}+L_{r} i_{r q}
\end{array}\right.
\end{gathered}
$$

By substituting (3) and (4) in (1) and (2) it is possible to obtain a state space model based on the current components.

The electromagnetic torque, the active and reactive power equations at the stator windings may be written as:

$$
T_{e}=\frac{3}{2} p\left(\lambda_{q s} i_{d s}-\lambda_{d s} i_{q s}\right)
$$




$$
\begin{aligned}
P_{s} & =\frac{3}{2}\left(v_{s d} i_{s d}+v_{s q} i_{s q}\right) \\
Q_{s} & =\frac{3}{2}\left(v_{s q} i_{s d}-v_{s d} i_{s q}\right)
\end{aligned}
$$

The system dynamics, neglecting the friction loss, is given by (8):

$$
J \frac{d w_{r}}{d t}+B w_{r}=T_{\text {mec }}-T_{e}
$$

The fifth order model of the DFIG is consisting of equations (1), (2) and (8).

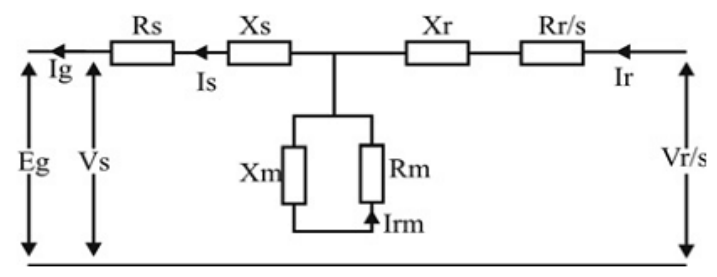

Fig. 1. Equivalent circuit of DFIG

\section{B. DFIG's Active and Reactive Power Flow}

As shown in the DFIG's equivalent circuit in Fig.1, in the synchronous reference frame, the stator and rotor voltage vectors can be expressed as

$$
\begin{gathered}
\overrightarrow{v_{s}^{s}}=R_{s} \overrightarrow{i_{s}^{s}}+\frac{d \overrightarrow{\psi_{s}^{s}}}{d t} \\
\overrightarrow{v_{r}^{s}}=R_{S} \overrightarrow{i_{r}^{s}}+\frac{d \overrightarrow{\psi_{r}^{s}}}{d t}
\end{gathered}
$$

From Fig.1, the DFIG's stator and rotor flux vectors can be expressed as

$$
\begin{aligned}
& \psi_{s}^{s}=L_{s} I_{s}^{s}+L_{m} I_{r}^{s} \\
& \psi_{r}^{s}=L_{r} I_{r}^{s}+L_{m} I_{s}^{s}
\end{aligned}
$$

Combining (3a) and ( $3 \mathrm{~b})$ yields

$$
I_{s}^{s}=\frac{L_{r} \psi_{s}^{s}-L_{m} \psi_{r}^{s}}{L_{s} L_{r}-L_{m}^{2}}=\frac{\psi_{s}^{s}}{\sigma L_{s}}-\frac{L_{m} \psi_{r}^{s}}{\sigma L_{s} L_{r}}
$$

where $\sigma=\left(\mathrm{L}_{\mathrm{s}} \mathrm{L}_{\mathrm{r}}-\mathrm{L}_{\mathrm{m}}^{2}\right) \mathrm{Ls} \mathrm{Lr}$ is the leakage factor.

The amplitude of the stator flux can also be calculated as

$$
\psi_{s}^{s}=\int\left(V_{s}^{s}-R_{s} I_{s}^{s}\right) d t=\int V_{s}^{s} d t
$$

Assuming the network voltage is constant and neglecting the stator resistor, the stator flux amplitude shown in (5) can be regarded as constant. Thus, combining (9), (10) and (12), the stator active and reactive power inputs from the network are given as:

$$
\begin{aligned}
& P_{s}=-\frac{3}{2} \frac{L_{m}}{\sigma L_{s} L_{r}} w_{1}\left|\psi_{s}^{r}\right|\left|\psi_{r}^{r}\right| \sin \theta \\
& Q_{s}=\frac{3}{2} \frac{w_{1}}{\sigma L_{s}}\left|\psi_{s}^{r}\right|\left(\frac{L_{m}}{L_{r}}\left|\psi_{r}^{r}\right| \cos \theta-\left|\psi_{s}^{r}\right|\right)
\end{aligned}
$$

where $\theta$ is the angle between the rotor and stator flux vectors.

Equation (14) indicates that the stator active and reactive powers can be controlled independently by adjusting $\psi_{\mathrm{rq}}$ and $\psi_{\text {rd }}$, respectively.

\section{DifFERENT DiRECT POWER CONTROL AlgorithMS}

The conventional DPC simply selects the switching states of the converter from an optimal switching table, based on the instantaneous errors between active and reactive powers and their references. This simple strategy can guarantees its good dynamic performance. However, the conventional DPC has several drawbacks which make it difficult to be applied in the DFIG-based wind power generation system. For example, the rotor voltages generated by a fixed and discrete switching table cannot satisfy the control precision of the active and reactive powers during maximum windenergy capturing. Furthermore, the electromagnetic torque vibration caused by the traditional DPC is much more significant than that in the vector control with the same sampling frequency. Moreover, the conventional DPC complicates the AC filter design because of its variable switching frequency. To overcome these drawbacks, several modified DPC strategies have been reported [10][12].

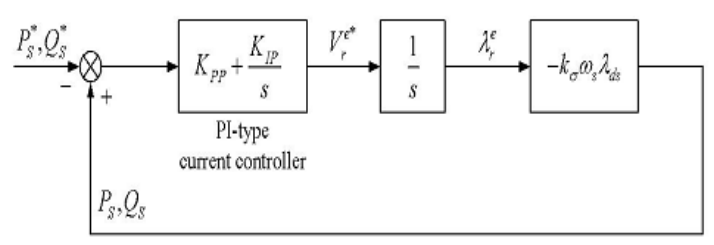

Fig. 2. Overall control system of the rotor flux DPC

In [10], the authors developed a modified DPC referred to as the output regulation subspaces based DPC (DPCORS), which was implemented via rotating the voltage vector with a pre-calculated angle for the purpose of refining the selection of control vector. DPC-ORS alleviates the THD value of phase currents under the grid voltage swell condition but cannot eliminate this distortion completely. In [11], the duty cycle of voltage vector within each sampling period was generated from a PI controller which minimizes electromagnetic torque fluctuation. But this controller makes the system structure more complex. A simple and effective method was proposed in [12] by calculating the required rotor controlling voltage within each sampling period directly based on the estimated stator flux, active and reactive powers and their errors. Meanwhile, a constant switching frequency was achieved by the space vector modulation (SVM) technique. However this method still encounters some problems such as overcurrent and electromagnetic torque vibration under grid voltage dips.

We can categorize different direct power algorithms into three major ones: rotor flux oriented DPC (RF-DPC), stator flux oriented DPC (SF-DPC) and predictive DPC (PDPC). 


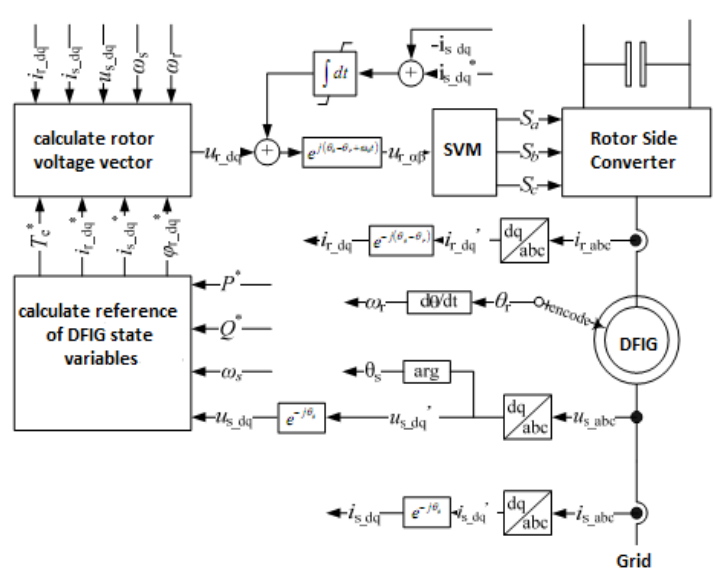

Fig. 3. Diagram of the stator voltage vector oriented direct power control

\section{A. Rotor Flux DPC (RF-DPC)}

In this method, the stator voltage vector should be determined firstly. Then the electrical and magnetic variables are all transformed into the synchronous reference frame with $\mathrm{d}$-axis aligned with stator voltage. The references of controlled variables are also calculated in this frame and finally the output rotor voltage vector can be determined.

Since the controlled variables are $\varphi_{\mathrm{dr}}$ and $\varphi_{\mathrm{gr}}$, this method is referred to as rotor flux DPC (RF-DPC). Dynamic response of the RF-DPC shows that keeping rotor flux as a constant could bring a short oscillation time and quick system recovery, the proof is given in the following section. Though $\varphi_{\mathrm{dr}}, \varphi_{\mathrm{gr}}$ cannot be measured directly, which may degrade the accuracy of the control strategy, RF-DPC could be applied to a DFIG which demands fast restoration. The RF-DPC is able to reduce oscillating time.

\section{B. Stator Flux DPC (SF-DPC)}

The method selects appropriate voltage vectors based on the stator flux position and active and reactive power errors. Thus, the difficulties associated with the rotor flux estimation are removed. The only machine parameter required by the DPC strategy is the stator resistance whose impact on the system performance is negligible. An optimal switching table has been derived and two three-level hysteresis comparators are used to determine the power errors. In order to achieve high dynamic control of active and reactive power, the active and reactive power states and stator flux position are used to determine which voltage vector is applied. Two three-level hysteresis comparators are used to generate the respective active and reactive power states. Diagram of SF-DPC is shown in Fig.3.

\section{Predictive DPC (PDPC)}

The method predicts the DFIG's stator active and reactive power variations within a fixed sampling period, which is used to directly calculate the required rotor voltage to eliminate the power errors at the end of the following sampling period. Space vector modulation is then used to generate the required switching pulses within the fixed sampling period that results in a constant switching frequency .One of the main features of the predictive DPC control technique is that reduced active and reactive power ripples are simultaneously guaranteed at steady state. It is very important to consider, accompanied to the vector selection strategy (two active and one zero vector) the switching criteria, i.e. the time intervals dedicated to each vector within the period, because they determine the ripple behavior of the reactive and active power. The time intervals will be calculated in order to minimize both ripples simultaneously.

In addition, since the active and the reactive power reference values depend on the application, they can take very different values, implying a different effect in the minimization. Consequently, the time intervals will be calculated after normalizing the reactive and the active powers to equal scale, so the minimization will be carried out by deducing an analytic expression based on normalized ripples. Added to this, several power minimization methods will be presented and compared, achieving different analytic expressions in order to calculate the time intervals dedicated for each vector.

Nowadays, Similar to DTC and DPC methods, model based predictive direct power control (MPDPC) incorporating SVM techniques has been proposed [13].

The principle of the MPDPC method involves the following aspects:

1) To directly calculate the required rotor voltage over a fixed sampling period based on the predictive power model ;

2) To generate appropriate voltage vectors over the fixed sampling period to approximate the effect of the required rotor voltage.

Thus, fast dynamic response of power control and a constant switching frequency are achieved. A typical schematic of MPDPC is revealed in Fig.4.

\section{SIMULATION RESULTS}

Simulations were carried out by Matlab/Simulink to compare the performance of three defined DPC algorithms. DFIG was rated at $2 \mathrm{MW}$ and its parameters are given in APPENDIX A. The switching frequency of the pwm converter was $3 \mathrm{kHz}$ and the rotor speed was fixed at 1.2 p.u. due to large inertia of the turbine.

It can be conclude that all of three DPC strategies can control the active and reactive powers without errors under steady state conditions, as shown in Fig. 6 and Fig.7.

In RF-DPC, since the Rotor supply frequency, which equals the DFIG slip frequency, can become very low, rotor flux estimation is significantly affected by the machine parameter variations.

In SF-DPC, since the stator (network) voltage is relatively harmonic-free with fixed frequency, a DFIG's estimated stator flux accuracy can be guaranteed. The control system is very simple, and the machine parameters' impact on system performance was found to be negligible. However, like other DPC methods, it has switching frequency that varies significantly with active and reactive power variations, machine operating speed(rotor slip), and the power controllers' hysteresis bandwidth. Apart from complicating the converter design, the stator side ac filter needs to be designed to eliminate broadband harmonics. With increased size and power loss, this significantly reduces filter efficiency.

MPDPC allows it to directly control the active power and 
the reactive power of the DFIM at constant switching frequency. Also, it has some privileges to the other two DPCs; such as improvement of transient performance, negligible parameter effects on system performance and its good dynamic response.

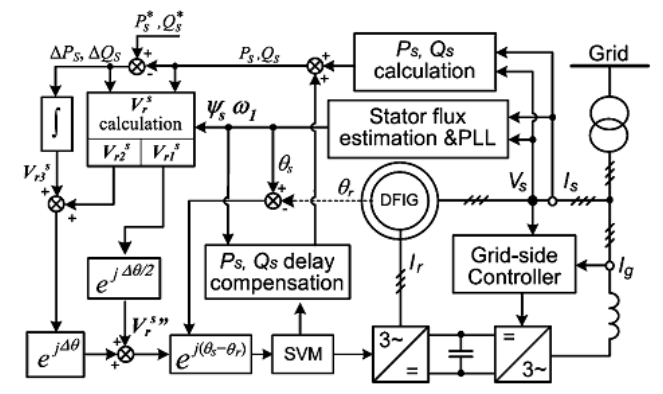

Fig. 4. A typical schematic of MPDPC

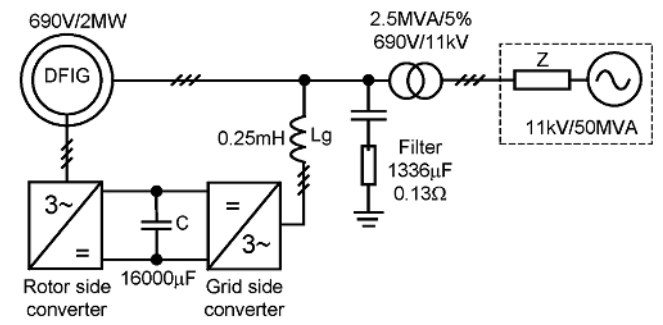

Fig. 5. Schematic diagram of the simulated system
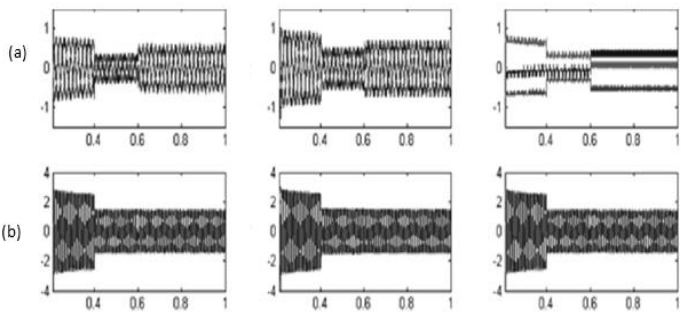

(c)
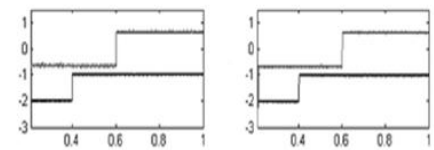

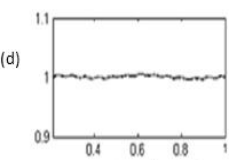

(A)

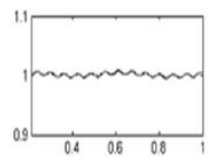

(B)
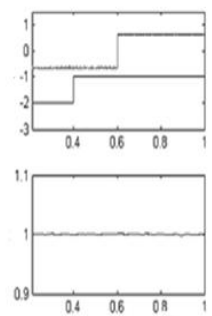

(c)

Fig. 6. Simulation results with fixed rotor speed A) RF-DPC B) SF-DPC C) MPDPC

a) Rotor currents (three phases) (kA) b) Stator currents (three phases) (kA) c) Active power (MW) \& Reactive power (MVAR) d) DC line voltage (kV)

\section{CONCLUSIONS}

This paper presented three kinds of DPC strategies for DFIG-based wind power generation system with theoretical analysis and detailed simulation investigation, some useful conclusions are drawn as follows:

1) As in the RF-DPC, stator flux should not be calculated; RF-DPC causes converter and filter design simplicity. It also improves the transient performance of controller.

2) SF-DPC, besides its converter and filter design complexity, improves system performance in compare with the RF-DPC.

3) Although the complex calculations in MPDPC cause the complexity of converter and filter design, but, its privileges, as stated in section IV, such as improved dynamic and transient performance make it a suitable controller for wind energy production.

In conclusion, the three DPC strategies proposed in this paper satisfy different requirements. Each one has some values besides some drawbacks showing in Table I.

\section{APPENDIX A}

TABLE

\begin{tabular}{|c|c|c|c|c|c|}
\hline & 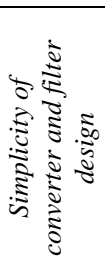 & 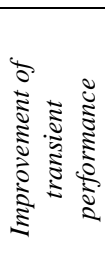 & 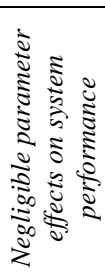 & 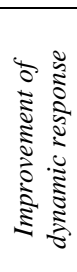 & 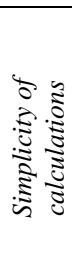 \\
\hline $\begin{array}{l}R F- \\
D P C\end{array}$ & $\checkmark$ & & & & $\checkmark$ \\
\hline$S F-D P C$ & & $\checkmark$ & & $\checkmark$ & \\
\hline$M P D P C$ & & $\checkmark$ & $\checkmark$ & $\checkmark$ & \\
\hline
\end{tabular}

TABLE II: PARAMETERS OF THE SIMULATED DFIG

\begin{tabular}{|c|c|}
\hline Rated power & $2 \mathrm{MW}$ \\
\hline Stator voltage & $690 \mathrm{~V}$ \\
\hline DC link voltage & $1200 \mathrm{~V}$ \\
\hline Stator/rotor turns ratio & 0.38 \\
\hline Lumped inertia constant & $0.2 \mathrm{~s}$ \\
\hline Number of pole pairs & 2 \\
\hline $\mathrm{R}_{\mathrm{s}}$ & $0.0108 \mathrm{pu}$ \\
\hline $\mathrm{R}_{\mathrm{r}}$ & $\begin{array}{l}0.0121 \mathrm{pu} \\
\text { (referred to the stator) }\end{array}$ \\
\hline $\mathrm{L}_{\mathrm{m}}$ & $3.362 \mathrm{pu}$ \\
\hline $\mathrm{L}_{\mathrm{ls}}$ & $0.102 \mathrm{pu}$ \\
\hline $\mathrm{L}_{\mathrm{lr}}$ & $0.11 \mathrm{pu}$ (referred to the stator) \\
\hline
\end{tabular}

\section{REFERENCES}

[1] W. Leonhard, "Control of Electrical Drives. London," U.K. Springer, 2001.

[2] R. Pena, J. C. Clare, and G. M. Asher, "Doubly fed induction generator using back-to-back PWM converters and its application to variable-speed wind-energy generation," Inst. Elect. Eng. Proc. Elect. Power Appl, vol. 143, no. 3, pp. 231-241, May1996. 
[3] H. Akagi and H. Sato, "Control and performance of a doubly-fed induction machine intended for a flywheel energy storage system," IEEE Trans. Power Electron., vol.17, no. 1, pp.109-116, Jan.2002.

[4] R. W. D. Doncker, S. Muller, and M. Deicke, "Doubly fed induction generator systems for wind turbines," IEEE Ind. Appl. Mag, vol. 8, no. 3, pp. 26-33, May/Jun.2002.

[5] I. Takahashi and T.Noguchi, "A new quick-response and highefficiency control strategy of an induction motor," Inst. Elect. Eng. Trans. Ind. Appl, vol. 22, no. 5, pp. 820-827, 1986.

[6] M. Depenbrock, "Direct self-control(DSC) of inverter-fed induction machine," IEEE Trans. Power Electron, vol. 3,no. 4, pp. 420-429, 1988.

[7] T. Noguchi, H. Tomiki, S. Kondo, and I. Takahashi, "Direct power control of PWM converter without power-source voltage sensors," IEEE Trans. Ind.Appl, vol. 34, no. 3, pp. 473-479, May/Jun.1998.

[8] G. Escobar, A. M. Stankovic, J. M. Carrasco, E. Galvan, and R. Ortega, "Analysis and design of direct power control(DPC) for a three phase synchronous rectifier via output regulation subspaces," IEEE Trans. Power Electron, vol. 18, no. 3, pp.823-830, May 2003.
[9] M. Malinowski, M. P. Kazmierkowski, S. Hansen, F. Blaabjerg, and G. D. Marques, "Virtual-flux-based direct power control of threephase PWM rectifiers," IEEE Trans. Ind. Appl, vol. 37, no. 4, pp.1019-1027, Jul./Aug.2001.

[10] G. Escobar, A. M. Stankovic, and J. M. Carraso, etal. "Analysis and Design of Direct Power Control (DPC) for a Three Phase Synchronous Rectifier via Output Regulation Subspaces," IEEE Trans.on Power Electronics, vol. 18, no. 3, pp. 8232830, 2003.

[11] W. Xin, C. D. Yue, Z. C. Yu, "A Torque Ripple Minimization Scheme in Direct Torque Control of Induction Motors," Techniques of Automation and Applications, vol. 24, no. 8, pp. 72-74, 2005.

[12] D. Zhi and L. Xu. "Direct Power Control of DFIG with Constant Switching Frequency and Improved Transient Performance," IEEE Trans. on Energy Conversion, vol. 22, no. 1, pp. 110-118, 2007.

[13] D. Zhi, L. Xu, and B. W. Williams, "Model-Based Predictive Direct Power Control of Doubly Fed Induction Generator," IEEE Trans. on Power Electronics, vol. 25, no. 2, FEBRUARY 2010. 